Sandra Dema Moreno

\section{Una pareja, dos salarios. El dinero y las relaciones de poder en las parejas de doble ingreso}

(Madrid, CIS/Siglo XXI, Colección Monografías, n.ำ225)

Este libro aborda una cuestión poco investigada en nuestro país, las relaciones de género en las parejas con dos salarios. Como es sabido, el aumento de la presencia de las mujeres en el mercado laboral es uno de los cambios sociales más importantes de las últimas décadas, y este hecho lleva a la autora del libro a preguntarse varias cuestiones cuya respuesta constituye el hilo conductor del mismo: ¿En los hogares en los que varones y mujeres trabajan fuera del hogar se genera una situación doméstica igualitaria? ¿El dinero garantiza la autonomía de las mujeres y genera igualdad en el hogar? El análisis de la desigualdad y de las relaciones de poder en la pareja que se desarrolla en este libro se enmarca en el contexto social cambiante que estamos viviendo en las sociedades contemporáneas.
La investigación* en la que se basa el libro de Sandra Dema se realizó a partir de entrevistas en profundidad a parejas de doble ingreso. Lo novedoso de esta obra es que, por un lado, investiga el vínculo entre el dinero y la desigualdad en el caso español y, por otro lado, se centra en aquellas parejas que supuestamente podrían ser más igualitarias, dado que son parejas en las que varones y mujeres tienen un empleo y, por tanto, ingresos propios.

En el libro se abordan fundamentalmente tres cuestiones. Por un lado, el significado del dinero y cómo los recursos económicos se constituyen o no en elementos de poder dentro de las relaciones de pareja. Por otro, los procesos a través de los cuales se produce y reproduce el poder en la pareja, tales como los modelos de gestión y administración del dinero en el hogar y el uso del dinero por parte de varones $y$ mujeres. $Y$, finalmente, las fórmulas de negociación y la toma de decisiones dentro de las parejas.

El libro se inicia con un primer capítulo teórico muy exhaustivo en el que la autora presenta

\footnotetext{
* La investigación a la que me refiero: «Parejas, dinero e individualización», fue llevada a cabo por un equipo de investigadoras e investigadores de la Universidad de Oviedo, de la Universidad de Umea (Suecia), de la Universidad Ludwig-Maximilian (Alemania), así como de las Universidades de Pensilvania y Carnegie Mellon (Estados Unidos), entre ellos/as la autora de este libro y la que suscribe esta reseña. El objetivo de este proyecto era averiguar si una de las principales características de la modernidad tardía, la creciente individualización, se ve reflejada en las vidas de las personas, particularmente cuando ambos miembros de la pareja ganan su propio dinero. Los hallazgos del proyecto en nuestro país se encuentran publicados en Capitolina Díaz Martínez, Cecilia Díaz Méndez, Sandra Dema Moreno y Marta lbáñez Pascual (2004), Dinero, amor e individualización. Las relaciones económicas en las parejas/familias contemporáneas, Oviedo, KRK Ediciones, y los de la investigación internacional, en Janet Stocks, Capitolina Díaz Martínez y Björn Halleröd (eds.) (2007), Modern Couples Sharing Money, Sharing Life, Houndmills y Nueva York, Palgrave Macmillan.
} 
las diferentes perspectivas teóricas que van a guiar su análisis, y que probablemente constituye el único texto en castellano que revisa la literatura sobre el poder y la desigualdad desde una perspectiva de género. En este capítulo, Sandra Dema propone adoptar un enfoque integrador que sea capaz de aprehender la complejidad y el dinamismo de las relaciones de género dentro del hogar. Dicho enfoque, que es el que guía su análisis, trata de vincular, por un lado, los aspectos macrosociológicos y microsociológicos presentes en las relaciones de pareja y, por otro lado, sugiere el análisis de las bases del poder y la desigualdad dentro de la pareja, mostrando también la dinámica de los procesos de ejercicio de poder. Por último, Sandra Dema no se limita a revelar las manifestaciones visibles y explícitas de la desigualdad y el poder, sino que saca a la luz las más implícitas y latentes.

El valor que aporta este libro reside, sobre todo, en su novedad, en el interés de su planteamiento teórico y en los resultados, que comentaré seguidamente, pero desde mi punto de vista no podemos pasar por alto otra cuestión fundamental, que es la metodología utilizada en esta investigación y el tipo de análisis que presenta. La autora se reconoce deudora, en el aspecto metodológico, del proyecto internacional mencionado anteriormente, del que formó parte y cuyas entrevistas son la base empírica y analítica del libro. En dicho proyecto investigador se llevaron a cabo entrevistas a parejas de doble ingreso, realizándose tres entrevistas a cada una de las parejas participantes en el estudio. Una primera entrevista conjunta a ambos miembros de la pareja y, posteriormente, una entrevista individual al va- rón y a la mujer por separado. Esta técnica de producción de información —que no se había llevado a cabo anteriormente- permite analizar de forma muy rigurosa lo que ocurre en el interior de la pareja. En el análisis de las entrevistas, Sandra Dema utiliza la técnica del estudio de caso, entendiendo y analizando cada grupo de entrevistas -la colectiva y las dos individuales - como un caso. Esto le permite construir una tipología de parejas muy interesante.

Si nos centramos en los resultados, una de las principales conclusiones de este libro está relacionada con la tipología que acabamos de mencionar. Según Sandra Dema, las parejas de doble ingreso - que no conforman un bloque homogéneo- se encuentran en un momento de transición a la modernidad en el que se pueden identificar tres modelos de pareja en función de las formas en las que se genera la desigualdad y se ejerce el poder en la relación. La autora identifica un primer modelo en el que la desigualdad y las relaciones de poder que se generan en la pareja están legitimadas por la tradicional socialización de género. En segundo lugar, nos descubre parejas con un ideal igualitario, en las que a pesar del ideal se dan relaciones de poder. Y, por último, señala la existencia de un tipo de parejas que establecen formas de relación tendentes a la igualdad. Encuentra la autora que en las parejas más igualitarias aparecen numerosas trabas que dificultan el funcionamiento de este tipo de relaciones, y aun cuando las parejas logran establecer un modelo que tienda a la simetría, en la práctica cotidiana se enfrentan a obstáculos de diverso tipo que entorpecen la construcción de la igualdad. 
A partir de la tipología que sugiere la autora se van explicando, en los capítulos dos, tres y cuatro del libro, las tres cuestiones fundamentales a las que hacía referencia anteriormente: el significado del dinero, los modelos de gestión y administración del dinero en el hogar y el uso del dinero por parte de varones y mujeres, y las fórmulas de negociación. En todas ellas la autora aporta una visión muy singular que permite avanzar en el conocimiento de estas cuestiones. Así, y por poner un ejemplo relacionado con el significado del dinero, en el libro se afirma que las desigualdades de género se reproducen independientemente de la cuantía de la aportación económica femenina al conjunto de los ingresos familiares, y muestra las evidencias encontradas a través del análisis de las parejas en las que los varones ganan menos que sus esposas.

Al referirse a los modelos de gestión y administración del dinero en el hogar, Sandra Dema parte de los estudios realizados por autoras tan conocidas como Jan Pahl o Carolyn Vogler, que identificaron cinco modelos de gestión del dinero en el hogar: el sistema de gestión conjunta, el sistema de gestión por parte del varón, el sistema de gestión por parte de la mujer, el sistema de gestión de una cantidad asignada y el sistema de gestión independiente. Pero, a diferencia de estas autoras, ella se centra en estudiar la dinámica interna que se genera en el interior de dichos modelos, llegando a afirmar que la desigualdad no depende tanto del tipo de modelo de gestión que se adopte como del funcionamiento del mismo. Ya que cualquiera de ellos puede favorecer o perjudicar la simetría, aunque unos la favorecen más que otros.
Y, finalmente, en la obra se aborda la cuestión de la negociación dentro de las parejas como una manifestación de las relaciones de poder tanto de las más explícitas o visibles como de las más ocultas o encubiertas. En el libro se plantea que varones y mujeres se encuentran en una posición diferente a la hora de adoptar decisiones, aunque hay diferencias sustanciales en los tres tipos de identificados. En las parejas más tradicionales, los roles de género convencionales hacen que varones y mujeres asuman diferentes responsabilidades con distinto valor y, por tanto, restrinjan la adopción de decisiones a esos ámbitos delimitados.

En las parejas que viven situaciones de desigualdad a pesar de su ideal igualitario, el consenso en la negociación es el modelo deseable. Por tanto, suelen poner en marcha mecanismos que favorezcan la toma de decisiones consensuada. Sin embargo, en este tipo de parejas las mujeres se encuentran en una posición de partida subordinada que les impide a ellas mismas considerarse y que sus maridos las consideren iguales en la negociación, por lo que, si bien se negocia, las mujeres ceden y el criterio del varón acaba siendo el dominante. Solamente en las parejas más igualitarias se logran condiciones de igualdad en la negociación.

Todos los aspectos que he tratado de destacar en esta breve reseña me llevan a recomendar con entusiasmo este libro que en nuestro país abre una importante vía de investigación.

\section{Capitolina DÍAZ MARTÍNEZ}

